\section{Forge Better Links with Governments} society. While a fair percentage own a $\mathrm{PhD}$ in economics, very few politicians are former physicists-though sometimes they are, and very successful, like Nato Secretary General Javier Solana-or scientists in general. I do not know whether the culprit is the abrupt end of the Renaissance due to religious wars or the later spread of Idealism, reluctant as it was to consider science as a part of culture.

The idealistic view of science as a purely practical endeavour, instrumental to defence or public health and communications, leads to the misconception that scientific discoveries and results are commodities which can be obtained or refused depending on the actual needs of the nation. This view leads to funding that is erratic, being exclusively linked to these needs rather than to the needs of science itself. But science is not a commodity: something you can buy and sell on the market if you don't have any.

One of the basic needs of science is continuity. Temporary cuts in funding lead to damage (in terms of loss of knowledge and expertise) that is long-term because, for instance, it encourages researchers and teachers to leave their science jobs. The next generation of researchers and teachers are then left trying to cope with this, with long-term harmful effects on the civil and economic status of the nation. On the other hand, modern science is pervading all aspects of our daily lives, with a Weltanschauung which is gradually superseding other philosophical and religious views, and imposing itself as a winning culture.

The question is: can the Western world still afford the scientific illiteracy of its rulers? It seems that the new economic competitors of Far- and South-East Asia are not so much affected by this problem. Technical schools there disseminate researchers into the workplace as well as future candidates for ruling positions. Experienced scientists are called back from the West to fill governmental positions (Nobel laureate Yuan Lee as science minister in Taiwan, for example). The highgrowth rate of these economies was fuelled by a trust in science. Even though the bubble in the East has now burst, and the growth could not be sustained, could Europe and North America not learn from their investments in science?

Practical responses of physical societies to this problem could be to promote the political commitment of experienced scientists, to strengthen their consultancy roles with governments and policy-makers, to have more access to media, tighter links with the industrial and economic world, etc. The latter aims are already on the agenda for the European Physical Society. However, we should consider that many politicians and government assistants holding a $\mathrm{PhD}$ in science passed through industrial jobs, private enterprises or consultant activities. Did we do enough in the past to attract to the EPS physicists operating within these important realities?

Another issue involving scientists on the global scale, which should be of interest to the largest physical societies, is that of planetary emergencies, at least for physical issues such as energy production and saving, nuclear waste management, detection, and monitoring of potentially dangerous asteroids and, last but not least, the control of nuclear weapon conversion. Much has been written (see for example Samuel Huntington's "The Clash of Civilisations and the Remaking of World Order") about the potential danger that highly aggressive peoples obtain weapons of mass-destruction. I have nothing to add to this except that dealing with the decommissioning of nuclear weapons and the smuggling of nuclear material requires at some stage scientific assistance-some hired physicists perhaps? Can a joint effort of physical societies do any good, both on the moral and practical levels? I think physical societies should discuss their cooperation and forge tighter links with concerned governments and agencies and expand their presence and action over the largest possible area of civil society.

Giorgio Benedek, Università Degli Studi Di Milano, Italy

\section{European Physical Society}

EPS Secretariat, BP 2136

F-68060 Mulhouse Cedex, France

phone $+33389329440, f a x+33389329449$

The EPS counts among its members some 3400 Individual Ordinary Members, and 72,000

National Society Members who belong to 36 national physical societies thoughout Europe.

\section{Managing Editor}

Toby Chapman

e-mail eneditor@univ-mulhouse.fr

\section{Subscriptions}

\section{ISSN print edition 0531-7479}

ISSN electronic edition 1432-1092

Volume 29: 6 issues will appear in 1998. Recommended annual subscription prices, institutions: DM 228.-; individuals: DM 98.Special rate for new individual subscribers: DM 78.- for one year. All prices plus carriage EPS Individual Ordinary Members receive Europhysics News free of charge. Members of EPS National Member Societies, except the German Physical Society and the Institute of Physics, UK, receive Europhysics News through their society. Subscriptions can either be placed via an agent or sent directly to:Springer-Verlag, Postfach 3113 40, D-10643 Berlin, Germany phone +493082787358 , fax +493082787448 e-mail subscriptions@springer.de Cancellation must be received by 30 September to take effect the following year.

\section{Electronic edition}

An electronic edition of this journal is available via the LINK Information Service

http://link.springer.de. You may contact us per e-mail access@link.springer.de or by fax $+49-62$ 21-4 87-288. Would you like to automatically receive per e-mail the table of contents with direct links to the respective abstracts as soon as a new issue is available via LINK? Then take advantage of our new, free service LINK Alert. For registration and further information just go to http://link.springer.de/alert.

\section{Production}

Springer-Verlag

3050 - Journal Production Department Lenore Grenzdörfer, Heidelberger Platz 3 D-14197 Berlin, Germany phone $+493082787750, f a x+493082787440$ e-mail grenzdoerfer@springer.de

\section{Advertisements}

Springer Verlag

E. Lückermann, S. Kindt, Postfach 311340 ,

D-14197 Berlin, Germany

phone +493082787741, fax +493082787300

e-mail anzeigen@springer.de

Advertising is charged according to space and position pro rata, based on DM 4000 .- for a full page, black and white. Rates on request. Discounts for EPS Associate Members. Deadline for orders: on request (normally four weeks before publication). 